\title{
Blood pressure variability: the effects of repeated measurement
}

\author{
Peter Burstyn* \\ Ph.D.
}

\author{
BARBARA O'DONOVAN* \\ B.Sc.
}

\author{
IAN Charlton $\dagger$ \\ Ph.D.
}

*School of Biochemical and Physiological Sciences, and $\dagger$ Department of Psychology, University of Southampt

\begin{abstract}
Summary
A series of 3 BP measurements were carried out on 2 groups of people. People not accustomed to BP measurements showed a decrease in pressure between the 1st and 3rd cuff inflation, while people trained to having their BP measured showed no such change.

Measurement of the BP of 111 people on 2 successive occasions 8 days apart showed that the mean BP of the whole group decreased between visits. Approximately one third of the people showed a drop in pressure bringing them from borderline hypertension to normotension between the 2 visits.

People whose BP dropped substantially between the 1st and 2nd visits achieved higher anxiety scores on a questionnaire than did the remainder of the sample. This may partially explain their labile BP.

Single measurements tend to overestimate the BP and the frequency of hypertension. Training experimental subjects by repeated measurement of their BP may be useful in preventing spurious BP changes unrelated to experimental manoeuvres.
\end{abstract}

\section{Introduction}

Blood pressures measured repetitively using semiautomated (Sokolow, 1979) and automated (Irving et al., 1974) equipment are lower than casual values obtained in office measurements. Irving et al. (1974) ascribed this discrepancy to the presence of the physician.

Systematic repetitive BP measurement has been shown to cause values to fall, but only in people with relatively high pressures (Mathieu et al., 1974). A recent review has suggested that, since first BP measurements are often made with the subject under some stress, it is not surprising that values obtained subsequently may be lower (Leading Article, 1980).

In recent experiments (Wright, Burstyn and

\footnotetext{
* Present address: Dept of Physiology, Godfrey Huggins School of Medicine, University of Zimbabwe, Salisbury, Zimbabwe.
}

Gibney, 1979; Burstyn, Hornall and Watchor色 1980), the BPs of normotensive volunteers were seêm to decrease with successive measurement. Since measurements were carried out 3 times weekl?, each being the mean of 3 cuff inflations, subjects were able to accommodate to the procedure quickl Their BPs settled to reproducible values after ofe week.

Observations made on the BPs of 3 group 8 people are reported here. They illustrate some ofipe effects of repetitive BP measurement, and offer support for the hypothesis that initial measurement may be made with the subject under some stress.

\section{Methods}

All BPs were measured using a Hawksley Randon? zero sphygmomanometer with the 5th sound take as the diastolic pressure. Subjects were seated quiet for at least $10 \mathrm{~min}$ before measurement. Three readings of the $\mathrm{BP}$ were taken over $4-5 \mathrm{~min}$, and the subjects were asked to clench their first gent between cuff inflations to prevent excessive blood pooling.

In the 1st study, the BPs of a class of 36 students were compared to those of 36 of the volunteers pa? ticipating in an experiment (Wright et al., 1979). The average age of the class was 22 years with $68 \%$ females, while the experimental volunteers (most students) averaged 25 years with $57 \%$ females. The BP measurements of the class were all made on 5 single afternoon in a quiet room adjacent to the student laboratory. The measurements on this experimental volunteers were spread over severâ days and made in an office. The same observers carried out both sets of measurements. The voluf teers, having had more than one week of contra measurements, are referred to as 'trained' while the class, most of whom had never before had their BP measured, are referred to as 'untrained'.

In the 2nd study, volunteers were solicited 
newspaper advertisement for a survey of diet and BP. All subjects aware of, or under treatment for, hypertension were excluded. Blood pressures were measured as above, except that values recorded are the means of 5 cuff inflations taking approximately $7 \mathrm{~min}$. The subjects returned 8 days later (range: 4-18 days) for a second set of measurements. Of the 111 people ( 52 males) who completed both visits, 94 were unknown to the authors. The average age of the group was $36 \pm 1.5$ years, with a range of 19-88 years. Diurnal variations in BP were avoided by taking most of the readings between 9 a.m. and 5 p.m., when BPs are relatively constant (Raferty and Millar-Craig, 1979). People who were only available in the evening had their BPs measured at the same time on both occasions.

A questionnaire was included in this study primarily as a check on random sampling. The items in the questionnaire dealt with certain personal habits and with tobacco and alcohol consumption as well as the component elements of 3 personality assessment scales. These were (a) manifest anxiety scale (Taylor, 1953), (b) personal confidence scale (Cattels, 1967), and (c) compliance or lie scale (Eysenck and Eysenck, 1977). The lie scale was used to exclude those subjects who attempted to create a 'good impression', rather than answer the questions truthfully. Each individual's score on (a) and (b) was used as a measure of anxiety/stability and confidence/ irritability respectively. All questionnaires were scored blind, and analyses made without prior knowledge of group identities.

Statistical comparisons between groups were by Student's ' $t$ ' test, or paired ' $t$ ' test, as appropriate.

\section{Results}

Table 1 shows that the systolic pressures of 'untrained' people decrease in the time required to carry out 3 cuff inflations. Decreases in systolic pressure were seen in 28 of the 36 individuals. By comparison, the systolic pressures of a similar group of people who were 'trained' by frequent BP measurement show no change between 1st and 3rd cuff inflations. Table 1 also shows that the systolic pressures of the 'trained' group are significantly lower than those of the 'untrained' group, despite the latter being slightly younger, and having a higher proportion of females.

Table 2 shows that the mean BP in the second study was significantly higher at first measurement

TABLE 2. Mean BPs ( \pm s.e. mean) of 111 volunteers taken on 2 separate visits 8 days apart. Pressure values are compared to each other using the ' $t$ ' test for pairs of values

\begin{tabular}{lll}
\hline & Systolic & Diastolic \\
\hline 1st visit & $129.2(1.6)$ & $85.1(1.0)$ \\
2nd visit & $124.9(1.5)$ & $82.0(0.9)$ \\
& $P<0.001$ & $P<0.001$ \\
\hline
\end{tabular}

than on a subsequent measurement some 8 days later. Altogether, 73 individuals had decreases in systolic pressure, although some of these differences were trivial. Table 3 compares the BPs of 36 individuals whose systolic pressures dropped by $10 \mathrm{mmHg}$ or more ('labile' BP) to those of the remaining 75 people ('stable' BP). The mean BP of the labile BP group was close to hypertensive values and considerably higher than that of the stable BP group on 1st visit. On the 2nd visit, the BPs of both groups were virtually identical. There were no differences between the 2 groups in age, height, or weight. The labile BP group was composed of equal numbers of males and females.

Subjects were not invited into the study if they were known to be hypertensive. Nevertheless, using the criteria set out by the Charlottesville Blood Pressure Survey (ages 15-55 years: diastolic pressure $\geqslant 90 \mathrm{mmHg}$; age $>55$ years: diastolic pressure $\geqslant 95 \mathrm{mmHg}$ for mild hypertension) (Carey et al., 1976), 31 individuals were found to be hypertensive on the 1st visit, and 13 were no longer hypertensive on the 2 nd visit. The 18 people who were mildly hypertensive on both visits did not differ from the rest of the population sample in age, height or weight, but the sex distribution in this group was different (15 male, 3 female).

TABLE 1. The first and third BP measurements (mean \pm s.e. mean) of a group of 3 taken over about 4 min in 36 'untrained' individuals and in 36 'trained' individuals who had their BPs measured 3 times/week for at least 1.5 weeks. Pressure values are compared to each other using either Student's ' $t$ ' test or the ' $t$ ' test for pairs of values where appropriate

\begin{tabular}{lrcc}
\hline & 'untrained' & 'trained' & \\
\hline $\begin{array}{l}\text { 1st cuff inflation } \\
\text { systolic } \\
\text { diastolic }\end{array}$ & $128.7(2.3)$ & $117.8(1.7)$ & $P<0.001$ \\
& $76.6(1.4)$ & $73.7(1.3)$ & $\mathrm{NS}$ \\
$\begin{array}{l}\text { 3rd cuff inflation } \\
\text { systolic } \\
\text { diastolic }\end{array}$ & & & \\
& $123.5(2.2)$ & $117.8(1.6)$ & $P<0.05$ \\
& $76.9(1.2)$ & $75.0(1.3)$ & $\mathrm{NS}$ \\
\hline
\end{tabular}

Paired ' $t$ ' test comparing 1 st and 3 rd systolic measurement for untrained subjects: $P<0.001$. 


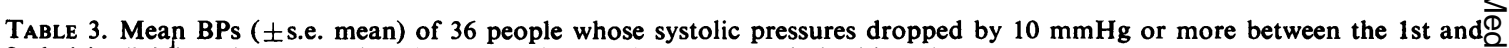
2nd visits (labile BP) compared to the BPs of the remaining 75 people (stable BP)

\begin{tabular}{|c|c|c|c|c|}
\hline & \multicolumn{2}{|c|}{ 1st visit } & \multicolumn{2}{|c|}{ 2nd visit } \\
\hline Labile BP & $\begin{array}{c}\text { Systolic } \\
137 \cdot 7(2 \cdot 9)\end{array}$ & $\begin{array}{l}\text { Diastolic } \\
88 \cdot 2(1 \cdot 5)\end{array}$ & $\begin{array}{c}\text { Systolic } \\
123 \cdot 5(2 \cdot 9)\end{array}$ & $\begin{array}{l}\text { Diastolic } \\
80 \cdot 2(2 \cdot 9)\end{array}$ \\
\hline Stable BP & $\begin{array}{l}125 \cdot 1(1.7) \\
P<0.001\end{array}$ & $\begin{array}{l}83.9(1.2) \\
P<0.05\end{array}$ & $\begin{array}{c}125 \cdot 1(1 \cdot 7) \\
\text { NS }\end{array}$ & $\begin{array}{c}82 \cdot 7(1 \cdot 1) \\
\text { NS }\end{array}$ \\
\hline
\end{tabular}

Both the systolic and diastolic pressures of the 'labile' BP group on the 1st and 2nd visit are statistically significantly different ${ }^{\mathcal{S}}$ from each other with $P<0.001$ (systolic) and $P<0.001$ (diastolic).

\begin{tabular}{|c|c|c|c|}
\hline & Labile BP & Stable BP & \\
\hline$n$ & 32 & 68 & \\
\hline Anxiety score & $3.8(1.5)$ & $3.0(1 \cdot 3)$ & $P<0.01$ \\
\hline Personal confidence score & $5 \cdot 8(2 \cdot 6)$ & $5.9(2 \cdot 5)$ & NS \\
\hline
\end{tabular}

Table 4 shows that the 'labile' BP group achieved a higher score on the anxiety scale than did the 'stable' BP group. The number of individuals actually scored is less than the total population sample because 10 were excluded on the basis of the lie scale. No differences can be seen in the personal confidence scores.

\section{Discussion}

The results show that repetitive measurement can reduce systolic pressure values with less effect on diastolic pressures. This is shown during the course of a single measurement session and over a pair of measurement sessions separated by several days. Similar results were reported by Mathieu et al. (1974) and Julius et al. (1974), but only for mildly hypertensive individuals. In the present population sample, fewer than $28 \%$ of the 'labile' BP group were mildly hypertensive on 1st measurement, suggesting that individuals with higher than average BPs do not contribute disproportionately to BP lability.

Several investigators have reported that re-measurement of the BP reduces the frequency of apparent hypertension in the population (Mathieu et al., 1974; Kilcoyne, Richter and Alsup, 1974; Carey et al., 1976). However, Wilber and Barrow (1972) found that the mean BP and the proportion of hypertensives in their sample changed little on remeasurement. Most of these BPs were measured in people's homes by 8 specially trained local women who might be expected to generate less anxiety than health workers unknown to the population. It is therefore interesting that the 36 people making up the 'labile' BP group in this survey scored higher \&nco the anxiety scale than did the rest of the population.sample. The reduction in BP on repetitive measure ment may be caused by increasing familiarity and greater relaxation.

No clear relationship has been found between⿳亠 hypertension and personality (Ostfeld and Lebovits, $\stackrel{\circ}{\circledR}$ 1959), but BP lability was correlated with excitability and anxiety (Ostfeld and Lebovits, 1960), and theO present results support this.

Frequent BP measurements are essential in experiments designed to observe changes in the BP. If subjects are not thoroughly trained to the measure- $\frac{0}{3}$ ment procedure during the control period, the effects:of subsequent experimental measurements may 3 . distort the result.

\section{References}

Burstyn, P.G., HoRnall, D. \& WatchoRn, C. (1980) Sodium and potassium intake and blood pressure. British음 Medical Journal, 309, 537.

CAREY, R.M., REID, R.A., AYers, C.R., LYNCH, S.S., N MCLAIN, W.L. \& VAUGHN, E.D. (1976) The Charlottesville Blood Pressure Survey. Value of repeated blood pressure measurements. Journal of the American Medical $\mathrm{W}$ Association, 236, 847.

Catrels, R.B. (1967) The Scientific Analysis of Personality Pelican, London.

EYSENCK, H.J. \& EYSENCK, S.B.G. (1977) The Manual of the Eysenck Personality Inventory. Hodder \& Stoughton, London.

Irving, J.B., KeRR, F., EwING, D.J. \& KirbY, B.J. (1974) Value of prolonged recording of blood pressure in assessment of hypertension. British Heart Journal, 36, 859. 
Julius, S., Ellis, C.N., Pascual, A.V., Matice, M., Hansson, L., HuYnor, S.N. \& SANDler, L.N. (1974) Home blood pressure determination. Value in borderline ('labile') hypertension. Journal of the American Medical Association, 229, 663.

Kilcoyne, M.M., Richter, R.W. \& Alsup, P.A. (1974) Adolescent hypertension. Detection and prevalence. Circulation, 50, 758.

Leading ARTICle (1980) Labile hypertension. British Medical Journal, 280, 4.

Mathieu, G., Biron, P., Roberge, F., Picard, J.M., Goulet, C. \& Allard, C. (1974) Blood pressure determinations during medical examinations: how many? Canadian Journal of Public Health, 65, 447.

OstFeld, A.M. \& Lebovits, B.Z. (1959) Personality factors and pressor mechanisms in renal and essential hypertension. Archives of Internal Medicine, 104, 43.
OstFeld, A.M. \& Lebovits, B.Z. Blood pressure lability: a correlative study. Journal of Chronic Diseases, 12, 428.

Raferty, E.B. \& Millar-Craig, M.W. (1979) Information derived from direct 24-hour recordings. In: Blood Pressure Variability (Ed by Clement, D.L.), ch. 10. MTP Press, Lancaster.

Sokolow, M. (1979) Data obtained with the ambulatory blood pressure recorder. In: Blood Pressure Variability (Ed by Clement, D.L.), ch. 2. MTP Press, Lancaster.

TAYLOR, J.A. (1953) A personality scale of manifest anxiety. Journal of Abnormal and Social Psychology, 48, 285.

Wilber, J.A. \& BARRow, J.G. (1972) Hypertension-a community problem. American Journal of Medicine, 52, 653.

Wright, A., Burstyn, P.G. \& Gibney, M.J. (1979) Dietary fibre and blood pressure. British Medical Journal, 2, 1541. 